\title{
Role of growth hormone in enchondroplasia and chondral osteogenesis: evaluation by X-ray of the hand
}

\author{
Lea Even', Björn Andersson², Berit Kriström ${ }^{3}$, Kerstin Albertsson-Wikland ${ }^{2}$ and Ze'ev Hochberg ${ }^{4}$
}

\begin{abstract}
BACKGROUND: The process of growth and maturation of long (radius and ulna) and short (metacarpals and phalanges) bones of the hand (enchondroplasia) differs from that of the carpal cuboid bones (chondral osteogenesis). This study aimed to assess the impact of growth hormone $(\mathrm{GH})$ on these two processes of bone maturation.
\end{abstract}

METHODS: Subjects of the study were 95 prepubertal children: 30 children with $\mathrm{GH}$ deficiency and 65 children with idiopathic short stature, aged 7.4 \pm 1.9 y (mean \pm SD) (trial registration number 98-0198-033). Bone maturation was assessed by the Greulich and Pyle method from X-rays obtained at the start and at 1 and 2 y of GH treatment, separately for carpals, long bones, and short bones, and was expressed as years of delay relative to chronological age.

RESULTS: At GH start, the delay in bone maturation in the GH-deficient group was significantly greater for carpals $(3.6 \pm 1.3 \mathrm{y})$ than for long $(3.0 \pm 1.3 \mathrm{y})$ and short $(1.7 \pm 1.1 \mathrm{y})$ bones. The delay was nonsignificantly greater for carpal bones in $\mathrm{GH}$-deficient subjects than in subjects with idiopathic short stature ( $3.6 \pm 1.3$ vs. $3.1 \pm 1.1 \mathrm{y}$, respectively) and was normalized after 2 y of GH treatment.

CONCLUSION: The dominant effect of GH was on chondral osteogenesis, with milder effect on enchondroplasia. A distinct delay in carpal and long-bone maturation, which normalizes during 2 y of GH treatment, was typical in $\mathrm{GH}$-deficient children. Therefore, separate carpal bone assessment in bone age reading is needed.

$\mathbf{T}$ he maturation of bones and their linear growth are due to the combination of chondral osteogenesis and enchondroplasia, defined jointly as enchondral ossification (1), occurring under the influence of several hormones and growth factors, with growth hormone $(\mathrm{GH})$ and insulin-like growth factor 1 playing important roles $(1,2)$. At birth, the primary ossification centers of the long bones and the short bones in the hand are well ossified; however, the cuboid carpal bones are still undergoing chondral osteogenesis. During early childhood, X-rays initially show chondral osteogenesis of the secondary ossification centers in the epiphyses of long and short bones, followed by the development and expansion of the growth plate cleft, a process referred to as enchondroplasia (2). Therefore, during childhood, there are differences in terms of maturation status between the long (radius and ulna) and short (metacarpals and phalanges) (enchondroplasia) bones of the hand on the one hand and the carpal bones (chondral osteogenesis) on the other $(3,4)$; maturation of the latter represents maturation of the cuboid vertebrae. We have previously hypothesized the importance of conducting a separate analysis of the carpal cuboid bones and the long and the short bones to enable better understanding of the physiology and endocrine control of bone maturation (1). Preliminary observations showed that the greatest delay in bone maturation within the hand occurs in the carpal bones for both GH deficiency (GHD) and GH insensitivity (Laron syndrome). This is consistent with the findings of Tanner et al. (4) during the development of the Tanner-Whitehouse 2nd edition method of bone evaluation, who noted that in children younger than $11 \mathrm{y}$, but not in older children, there were differences in the maturation status of the long and the short bones relative to the carpal cuboid bones in many conditions. Yet, Greulich and Pyle state that "By and large, when there is a discrepancy between the carpal bones and the distal centers, greater weight should be assigned to the distal centers because they tend to correlate better with growth potential" $(3,5)$.

Skeletal maturation and linear growth are delayed in children with GHD (6-8), and treatment with GH advances bone maturation because it ameliorates linear growth (9). Similar results have been observed in children with idiopathic short stature (ISS) (10), in whom the magnitude of bone age delay was associated with the growth outcome (10). However, all current methods for the assessment of skeletal maturation $(3,11,12)$ average or summarize bone maturation to give a unified bone age, thereby losing information on any variability among individual bones (13). Evaluation of maturation for individual bones allows the observer to differentiate the effects of GH on different growth and maturation processes. 


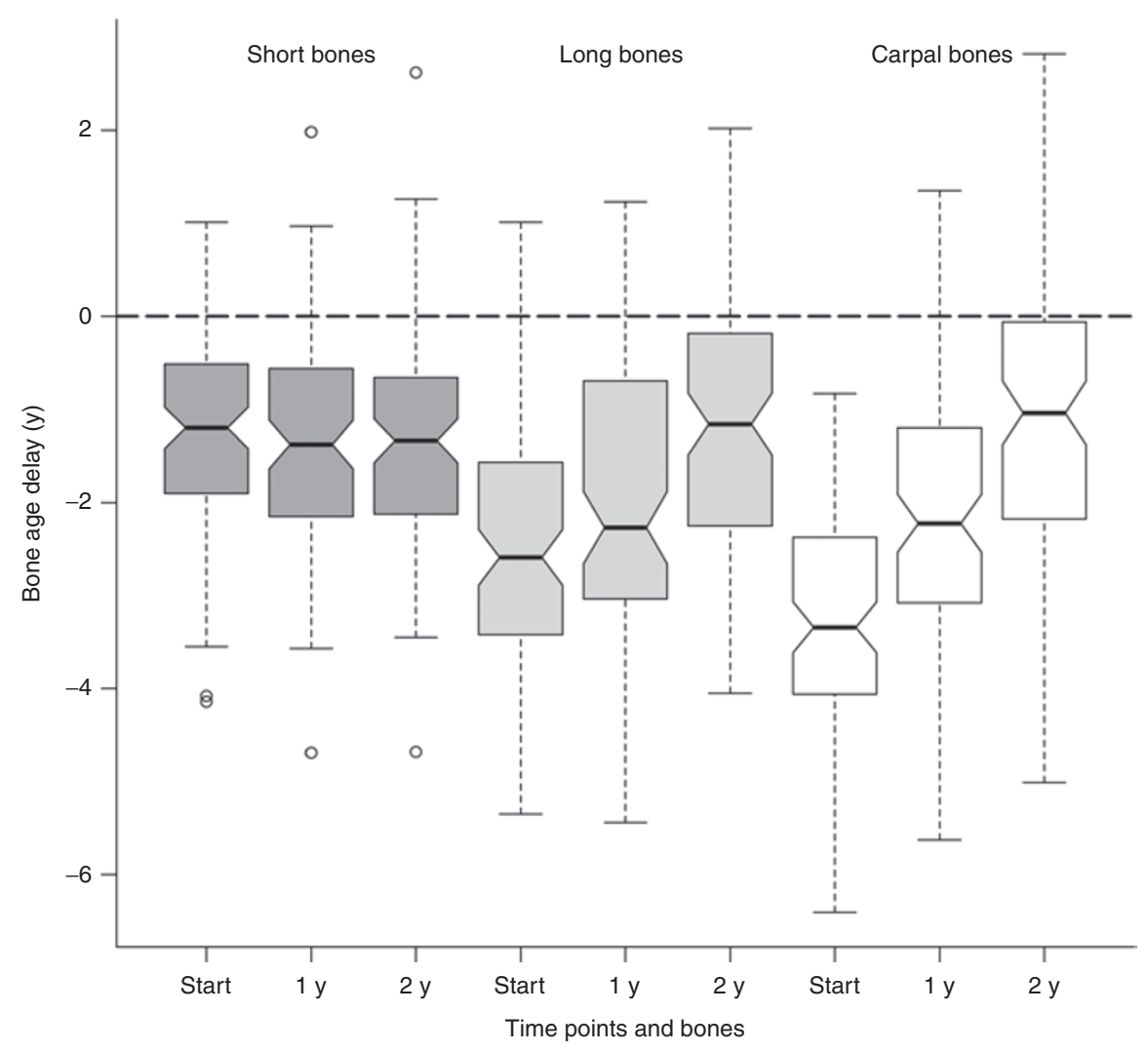

Figure 1. Bone age delay in years before start, at $1 \mathrm{y}$, and at $2 \mathrm{y}$ of GH treatment for the total group of children with GHD and ISS: short bones (left), long bones (middle), and carpal bones (right). The box plot visualizes the median (waist) and the 75 and $25 \%$ quartiles, whereas the whiskers represent the $\pm 1.5 \times$ intraquartile range.

The objective of this study was to assess the differential impact of GH on long against cuboid bone maturation in children with GHD and ISS. Children were assessed at the start and at 1 and $2 \mathrm{y}$ of GH treatment to explore the impacts of GH treatment on enchondroplasia and chondral osteogenesis separately.

\section{RESULTS}

\section{Total Group}

Before start of GH treatment. Bone maturation was delayed before the start of GH treatment in all three groups of bones (Figure 1, Table 1). The delay was greater for the carpal bones $(3.2 \pm 1.2$ y) compared with the long bones $(2.6 \pm 1.3 \mathrm{y} ; P=$ $0.0007)$ and the short bones $(1.3 \pm 1.1 \mathrm{y} ; P<0.0001)$ of the hand (Figure 1, Table 1).

On GH treatment. The bone ages of the carpal cuboid bones and the long bones, but not of the short bones, matured beyond the expected chronological age change $(P<0.0001)$ during $2 \mathrm{y}$ of GH treatment. At $2 \mathrm{y}$ of GH treatment, the bone age of the carpal bones had matured by $4.2 \pm 1.3 \mathrm{y}$, that of the long bones by $3.4 \pm 1.3 \mathrm{y}$, and that of the short bones by $1.9 \pm 0.6 \mathrm{y}$ (Figure 2, Tables 1 and 2).

\section{GHD vs. the ISS Groups}

Before start of GH treatment. Bone maturation before the start of GH treatment was delayed in children with GHD more than in children with ISS. For children with GHD, maturation was delayed by $3.6 \pm 1.3 \mathrm{y}$ for the carpals, $3.0 \pm 1.3 \mathrm{y}$ for long bones, and $1.7 \pm 1.1$ y for short bones (Tables 1 and 2). For children with ISS, bone maturation was delayed by $3.1 \pm 1.1$ $\mathrm{y}$ for the carpals, $2.4 \pm 1.3 \mathrm{y}$ for the long bones $(P=0.025 \mathrm{vs}$. children with GHD), and $1.1 \pm 1.1 \mathrm{y}$ for the short bones $(P=$ 0.011) (Tables 1 and 2).

On GH treatment. Bone maturation was similar in children with GHD and in children with ISS over the course of $2 y$ of GH treatment: carpal bones matured by $4.0 \pm 1.2 \mathrm{y}$ in the GH-deficent group and by $4.2 \pm 1.4 \mathrm{y}$ in the ISS group (not significant); long bones had matured by $3.4 \pm 1.2 \mathrm{y}$ in the $\mathrm{GH}$-deficent group and by $3.4 \pm 1.4 \mathrm{y}$ in the ISS group; and short bones matured by $1.9 \pm 0.6 \mathrm{y}$ in the GH-deficent group and $1.9 \pm 0.5 \mathrm{y}$ in children with ISS (Tables 1 and 2). Bone maturation of the carpal and long bones was normalized by treatment within the 2-y period of GH treatment.

\section{Multivariate Analysis}

Multiple regressions were applied to identify the most important variables for bone maturation during 2 y of GH treatment (variables included from Tables 1 and 3). Analysis revealed (Table 4) that the strongest predictors of maturation for the carpal bones were age at start of treatment (+; the older children matured faster) and gender (girls matured faster than boys) $\left(R^{2}=0.42\right.$, cross-validated $\left.R^{2}=0.39\right)$. For the long bones, the strongest predictors were age at start of treatment 
Table 1. The effect of GH treatment on bone age ("years") before treatment, at $1 \mathrm{y}$, and at $2 \mathrm{y}$ of GH treatment

Greulich and Pyle measurements, in years

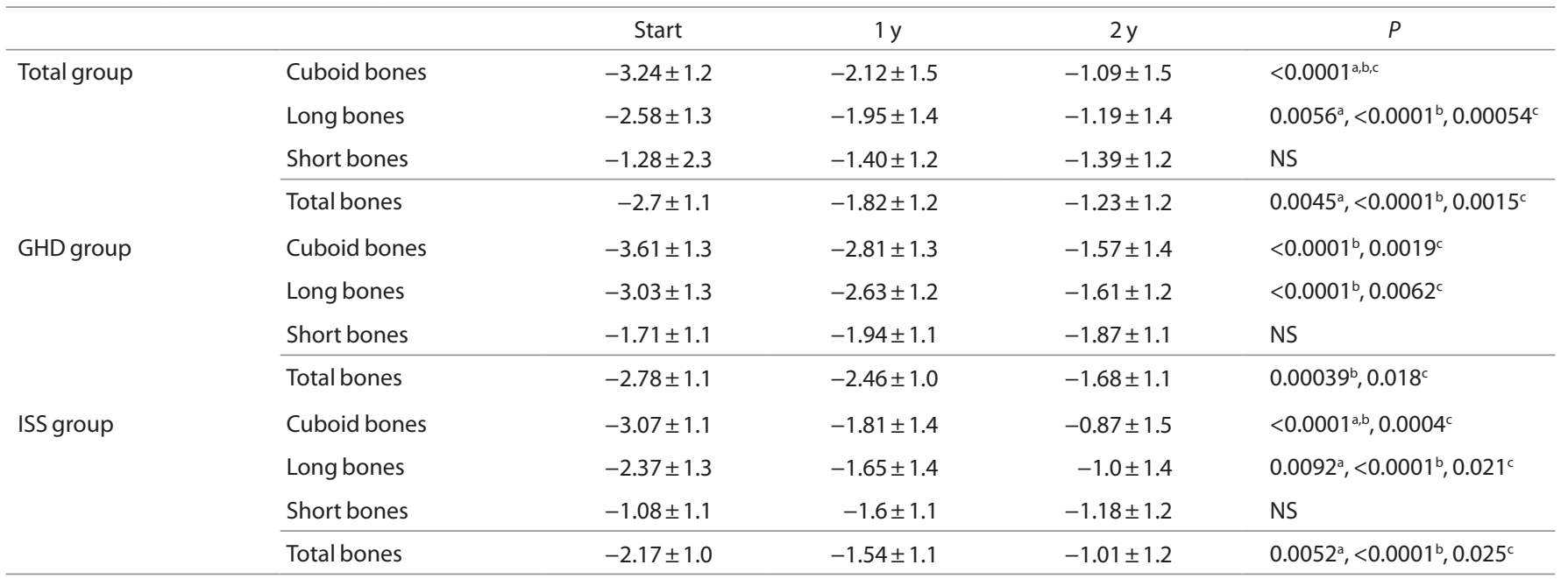

Values are shown as mean \pm SD for the total sample, the GHD group, and the ISS group for the carpal cuboid bones, the long bones, and the short bones, separately and in total (years). GH, growth hormone; GHD, GH deficiency; ISS, idiopathic short stature; NS, not significant. 0 y = baseline.

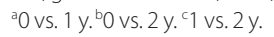

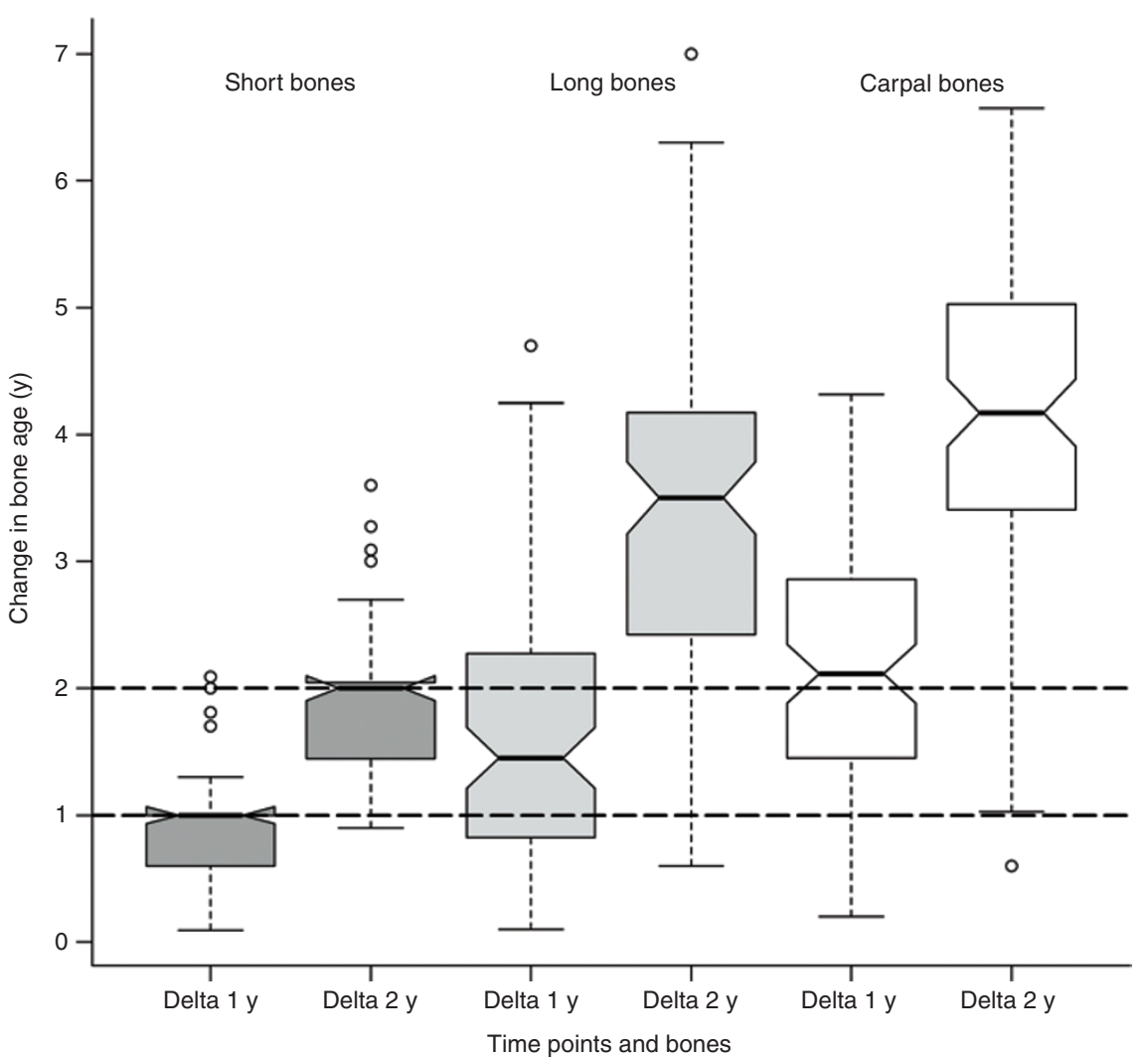

Figure 2. Change in bone age (in years) at $1 \mathrm{y}$ and at $2 \mathrm{y}$ of GH treatment for the total group of children with GHD and ISS: short bones (left), long bones (middle), and carpal bones (right). The box plot visualizes the median (waist) and the 75 and $25 \%$ quartiles, whereas the whiskers represent the $\pm 1.5 \times$ intraquartile range.

$(+)$, gender (girls > boys), and bone age of the long bones at start of treatment $(-)\left(R^{2}=0.40\right.$, cross-validated $\left.R^{2}=0.35\right)$. For the short bones, age at the start of GH treatment $(+)$ was the only significant predictor of bone maturation $\left(R^{2}=0.15\right.$, crossvalidated $R^{2}=0.10$ ).

\section{DISCUSSION}

Here, we show that the delay in bone maturation in children with GHD and ISS was most evident from assessment of the carpal bones of the hand. The maturation delay was greater when these bones were assessed relative to other bones in the 
Table 2. Bone maturation at 1 and $2 \mathrm{y}$ of GH treatment

\begin{tabular}{|c|c|c|c|c|}
\hline \multicolumn{2}{|c|}{ Change in bone age, years } & \multirow{2}{*}{$\frac{1 y}{2.14 \pm 1.0}$} & \multirow{2}{*}{$\frac{2 y}{4.15 \pm 1.3}$} & \multirow[t]{2}{*}{$\begin{array}{l}P<\text { at } 1 \text { y/2 y } \\
\text { within group } \\
\text { cuboid vs. }\end{array}$} \\
\hline Total group & Cuboid bones & & & \\
\hline & Long bones & $1.63 \pm 1.0$ & $3.38 \pm 1.3$ & 0.0001 \\
\hline & Short bones & $0.88 \pm 0.4$ & $1.87 \pm 0.6$ & 0.0001 \\
\hline & Total bones & $1.55 \pm 0.6$ & $3.13 \pm 0.9$ & 0.0001 \\
\hline \multirow[t]{4}{*}{ GHD group } & Cuboid bones & $1.85 \pm 0.8$ & $4.04 \pm 1.2$ & \\
\hline & Long bones & $1.43 \pm 0.9$ & $3.42 \pm 1.2$ & NS \\
\hline & Short bones & $0.84 \pm 0.4$ & $1.85 \pm 0.5$ & 0.0001 \\
\hline & Total bones & $1.37 \pm 0.6$ & $3.10 \pm 0.8$ & $\mathrm{NS} /=0.002$ \\
\hline \multirow[t]{4}{*}{ ISS group } & Cuboid bones & $2.26 \pm 1.0$ & $4.19 \pm 1.2$ & \\
\hline & Long bones & $1.71 \pm 1.0$ & $3.36 \pm 1.4$ & 0.001 \\
\hline & Short bones & $0.90 \pm 0.4$ & $1.89 \pm 0.6$ & 0.0001 \\
\hline & Total bones & $1.62 \pm 0.6$ & $3.15 \pm 0.9$ & 0.0001 \\
\hline
\end{tabular}

Values are shown as mean \pm SD for the total sample, the GH-deficent group, and the ISS group for the carpal cuboid bones, the long bones, and the short bones, separately and in total (years).

GH, growth hormone; GHD, GH deficiency; ISS, idiopathic short stature; NS, not significant. Significance between groups was NS, despite the result at $1 \mathrm{y}$ for cuboid bones in the comparison GHD vs. ISS being $P=0.045$.

hand. Furthermore, data showed that $2 \mathrm{y}$ of GH treatment significantly advanced maturation of the carpal cuboid bones and, to a smaller degree, the long bones of the hand, normalizing bone age for both these bone groups.

As the Tanner-Whitehouse 2nd edition (4) method for evaluation of bone maturation was developed, Tanner et al. (4) realized that the long- and short-bone readings (RUS for Radius Ulna Short bones) were in discrepancy with the readings for carpals in many clinical conditions. They proposed that the mean difference between carpals and RUS in normal girls was $0 \mathrm{y}$ during 2-11 y of age, with an SD of 0.7-1.0 y. In the current study, we took a similar approach, expanded it to readings of individual bones, and attempted to obtain an insight from these readings into the effect of $\mathrm{GH}$ on bone maturation and growth retardation in GHD. In order to deal with bone age of individual bones, and to give the readings in terms of years of delay for each individual bone, we had to use the Greulich and Pyle method (5). The two methods of bone age assessment as used in clinical practice do not give equivalent estimates of bone age (14). Yet, this article averaged bones and ignored the carpals. By convention, the emergence on an X-ray film of primary ossification centers of the cuboid carpal bones or secondary ossification centers in the epiphyses of both long and short bones during early childhood is referred to as the process of osteogenesis. It is followed by development and expansion of the growth plate cleft, a process referred to as enchondral ossification, or enchondroplasia (2).

$\mathrm{GH}$ and insulin-like growth factor 1 have direct effects on the longitudinal growth of long bones and on the centripetal growth of cuboid bones (including the carpal bones and the cuboid bones of the spine). They markedly enhance both DNA synthesis and the expression of cartilage-specific type II collagen, proteoglycan, chondrocalcin, and $100-\mathrm{kDa}$ protein; they accelerate enchondroplasia, induce chondral osteogenesis, and transform the cartilaginous nodule into bone, as previously reviewed (1). Here, we show that separate readings of bone maturation for the different types of bones in the hand reflect these physiological considerations. Results showed that GH is a major stimulator of chondral osteogenesis, and, to a lesser extent, it stimulates enchondroplasia: GHD is associated with a greater impairment of the former than of the latter, and $\mathrm{GH}$ treatment advances the former more than the latter. Multiple regression analyses of the explained variance for the different bone groups showed that the strongest predictors of maturation status of the carpal bones were age at start of treatment, i.e., the older the child, the faster is the maturation, and gender, i.e., a girl matured faster than a boy. In that respect, children with ISS and those with GHD have similar responses, as expected from the known overlap between children with these diagnoses $(15,16)$. This might indicate an influence by steroid hormones before secondary characteristics are observed (17).

The cuboid bones are often ignored in assessments of bone maturation. In the recently developed automatic computerized reading method, maturation of the carpal bones was not even measured $(18,19)$. This warrants consideration because the maturation status of the carpal bones is an important surrogate for the status of other cuboid bones, mostly the vertebrae that make a considerable contribution (approximately $40 \%$ ) to adult height. Cuboid bones develop through a pure process of chondral osteogenesis; centripetal ossification of the hyaline cartilage occurs through the osteogenetic phases of cartilage hypertrophy and calcium deposition, followed by resorption and formation of bone (1). We have previously shown that the maturation of carpal bones is markedly regulated by thyroid hormones, whereas sex steroids have little impact on their maturation (1). We now show a radiological evidence for the central role of GH in this process and the beneficial impact of GH treatment in patients with delayed bone age. Indeed, GH was shown to have specific effects on growth plate cells, as already reviewed (20). In a rat model, GH enhances the mobilization of tartrate-resistant acid phosphatase-positive osteoclasts that are active in cartilage and bone resorption in enchondral osteogenesis (21). Whereas the primary ossification centers of long bones are well ossified at birth, the carpal cuboid bones of the hands portray a unique opportunity to observe primary ossification centers in their making. The current results show that these bones must not be ignored in the reading of bone maturation as they are strongly influenced by GH.

\section{Conclusion}

Analysis of bone maturation from X-rays can provide the clinician with a lot more than a single value for "bone age." It provides a glimpse into the biology of the bones and their mechanisms of growth, as well as the effects of hormones and growth factors. The observation that the delay in bone age in children with GHD and ISS was most pronounced for the carpal bones highlights how important it is that these bones are assessed independently from the long and the short bones in bone age measurements for these patients. 
Table 3. Auxological data of the study subjects

\begin{tabular}{|c|c|c|c|c|c|c|c|c|c|}
\hline \multicolumn{4}{|c|}{ Total group ( $n=95 ; 28$ girls and 67 boys) } & \multicolumn{3}{|c|}{ ISS ( $n=65 ; 20$ girls and 45 boys) } & \multicolumn{3}{|c|}{$\mathrm{GHD}(n=30 ; 8$ girls and 22 boys) } \\
\hline Variables & Median & Minimum & Maximum & Median & Minimum & Maximum & Median & Minimum & Maximum \\
\hline \multicolumn{10}{|l|}{ At birth } \\
\hline Length SDS & -0.66 & -2.52 & 1.68 & -0.66 & -2.52 & 1.68 & -0.74 & -2.35 & 1.63 \\
\hline MPHSDS & -0.97 & -2.44 & 0.88 & -0.96 & -2.44 & 0.88 & -1.02 & -2.15 & 0.14 \\
\hline Age (years) & 7.14 & 3.05 & 10.94 & 7.03 & 3.57 & 10.92 & 7.88 & 3.05 & 10.94 \\
\hline Height SDS & -2.62 & -4.10 & -1.90 & -2.63 & -4.10 & -1.90 & -2.59 & -3.65 & -1.99 \\
\hline Weight SDS & -2.31 & -4.13 & 0.26 & -2.41 & -4.13 & -0.66 & -2.08 & -3.80 & 0.26 \\
\hline BMISDS & -0.50 & -3.35 & 2.11 & -0.61 & -3.35 & 1.61 & -0.32 & -1.80 & 2.11 \\
\hline $\mathrm{GH}_{\max } \mathrm{AITT}(\mathrm{mU} / \mathrm{l})$ & 24.4 & 5.4 & 89.9 & 28.9 & 10.7 & 89.9 & 22.2 & 5.4 & 31.9 \\
\hline \multicolumn{10}{|l|}{ At $2 y$ of treatment } \\
\hline Height SDS & -1.45 & -3.00 & 0.20 & -1.45 & -3.00 & 0.20 & -1.48 & -2.42 & -0.23 \\
\hline Delta height SDS $2 y$ & 1.19 & 0.37 & 2.30 & 1.19 & 0.37 & 2.30 & 1.28 & 0.51 & $2-12$ \\
\hline BMI SDS & -0.14 & -2.45 & 2.03 & -0.13 & -2.45 & 1.85 & -0.27 & -2.14 & 2.03 \\
\hline IGF-1 SDS & 1.57 & -1.48 & 4.21 & 1.79 & -0.55 & 3.71 & 1.56 & -1.48 & 4.21 \\
\hline
\end{tabular}

Table 4. Multiple regression analysis

\begin{tabular}{|c|c|c|c|c|c|c|}
\hline Dependent variable & $R^{2}$ & $C V R^{2}$ & $P<$ & Predictors & Coefficient & $P<$ \\
\hline \multirow[t]{2}{*}{ 2-y maturation in carpal bones } & 0.42 & 0.39 & 0.00001 & Intercept & -1.3303 & $P=0.0030$ \\
\hline & & & & Gender & 0.5815 ; girls $>$ boys & $P=0.014$ \\
\hline \multirow[t]{3}{*}{ 2-y maturation in long bones } & 0.40 & 0.35 & 0.00001 & Intercept & -1.77010 & $P=0.0003$ \\
\hline & & & & Gender & 1.00581 ; girls $>$ boys & $P=0.0002$ \\
\hline & & & & B-age of long bones at start & -0.53887 & 0.00001 \\
\hline \multirow[t]{2}{*}{ 2-y maturation in short bones } & 0.15 & 0.10 & 0.0001 & Intercept & -0.95518 & 0.0001 \\
\hline & & & & C-age at start & 0.11318 & 0.0001 \\
\hline
\end{tabular}

Explained variance of the bone age maturation status of the carpal cuboid bones, the long bones, and the short bones.

B-age, bone age; C-age, chronological age; CV, cross-validated.

\section{METHODS}

\section{Ethical Considerations}

The protocol for the clinical trial from which the study population was taken was approved by the ethics boards of the Universities of Gothenburg (for patients from Gothenburg and Halmstad), Umeå, Uppsala, and Lund, besides the Medical Product Agency of Sweden. Written informed consent was obtained from all parents and from the children if they were old enough. The trial was performed in accordance with the Declaration of Helsinki and Good Clinical Practice guidelines.

\section{Study Population}

This analysis included patients in the per-protocol population of the GH dose clinical trial (trial registration number 98-0198-003), as described previously (15) (Table 3 ). This group comprised 128 short ( $<-2$ SD according to Swedish reference) (23) prepubertal children of Caucasian origin receiving $\mathrm{GH}$ treatment. X-rays were available for
Greulich and Pyle evaluation both at the start and at 1 and $2 \mathrm{y}$ of GH treatment for 95 of these children -28 girls, aged $7.1 \pm 1.4$ y (mean \pm SD) and 67 boys, aged $7.5 \pm 2.1 \mathrm{y}$ at start. A maximum peak $\mathrm{GH}$ level $\left(\mathrm{GH}_{\max }\right)$ corresponding to $10 \mu \mathrm{g} / \mathrm{l}(24)$ on an arginine-insulin tolerance test and $/$ or during a 24-h GH profile was used to classify the patients as having either GHD $(n=30)$ or ISS $(n=65)$. Serum insulin-like growth factor 1 was measured and transformed into standard deviation score (SDS) according to our laboratory reference (25).

\section{Analyses of X-Rays of the Hand}

The maturation status of each bone of the hand was assessed from $\mathrm{X}$-rays by two observers separately (an experienced pediatric endocrinologist and a professional experienced bone age technician) according to the radiographic atlas of Greulich and Pyle $(3,5)$, as previously described (22). Bone age was calculated separately for the carpal bones (i.e., the nine cuboid bones not seen at birth), the long 
bones of the hand, and the short bones and was expressed in terms of years of delay relative to chronological age.

\section{Growth Evaluation}

Growth was evaluated with reference to the childhood component (26) of the Swedish population-based growth data (23). Height and weight were expressed as a SDS value (23) and so were the BMI (27) and parental height (28). Height and weight measurements were available from 1 y before the start of treatment, at start, and after every 3 months during the $2 \mathrm{y}$ of GH treatment (Table 3 ).

\section{Statistics}

Mean bone age data were compared between different treatment years for the total population, the GHD group, and the ISS group. The significance of differences between two continuous variables was tested using Student's $t$-test if the data were normally distributed and using the Wilcoxon signed-rank test when the data were not normally distributed. For continuous variables involving three or more groups, an analysis of variance with Tukey's honestly significant difference post hoc test was conducted. Factors predictive of bone maturation were determined using a multiple regression analysis. Variables that had a $P$ value $<0.10$ in the bivariate analysis, when tested for association with bone maturation, were entered into the regression equation and eliminated in a backward stepwise fashion. Ten-fold cross-validations were applied to test the stability of the models. Statistical analyses were performed using R software (version 2.15.2, The R project).

\section{ACKNOWLEDGMENTS}

The authors thank all the patients, parents, and study teams involved in this research. We also thank the investigators of trial registration number 98-0198-003, Kerstin Albertsson-Wikland, Stefan Aronson, Jan Gustafsson, Sten A. Ivarsson, Berit Kriström, and Torsten Tuvemo. The language editing by Harriet Crofts is highly appreciated.

\section{STATEMENT OF FINANCIAL SUPPORT}

The investigator-initiated and sponsored study (trial registration number 98-0198-003) was supported by an unrestricted research grant from Pharmacia/Pfizer, the Swedish Research Council grant no. 7509, and grants from the Wilhelm \& Martina Lundgrens Foundation, Wera Ekströms Foundation for Pediatric Research, The Foundation Växthuset for Children, Governmental University Hospital (ALF), and West Sweden Region (VGR). The only funding institution was Göteborg Pediatric Growth Research Center, Department of Pediatrics, Institute of Clinical Sciences, Sahlgrenska Academy, University of Gothenburg, Sweden.

Disclosure: L.E., B.A., and Z.H. have nothing to declare. B.K. has received lecture and consultation honoraria from Ipsen, Merck Serono, Novo Nordisk, Pfizer, and Sandoz. K.A.-W. received an unrestricted research grant from Pharmacia/Pfizer until 2005.

\section{REFERENCES}

1. Hochberg Z. Endocrine Control of Bone Maturation. Basel, Switzerland: Karger, 2002.

2. Hunziker EB, Wagner J, Zapf J. Differential effects of insulin-like growth factor I and growth hormone on developmental stages of rat growth plate chondrocytes in vivo. J Clin Invest 1994;93:1078-86.

3. Greulich WWW, Pyle SI. Radiographic Atlas of the Hand and Wrist. Stanford, CA: Stanford University Press, 1959.

4. Tanner JM, Whitehouse RH, Cameron N, Marshall WA, Healy MJR, Goldstein H. Assessment of Skeletal Maturity and Prediction of Adult Height (TW-2 Method). 2nd edn. London: Academic Press; 1983.

5. Greulich WW, Pyle SI. Radiographic Atlas of Skeletal Development of the Hand and Wrist. 2nd edn. Stanford, CA: Stanford University Press, 1991.

6. Saggese G, Baroncelli GI, Bertelloni S, Cinquanta L, Di Nero G. Effects of long-term treatment with growth hormone on bone and mineral metabolism in children with growth hormone deficiency. J Pediatr 1993;122:37-45.
7. Shore RM, Chesney RW, Mazess RB, Rose PG, Bargman GJ. Bone mineral status in growth hormone deficiency. J Pediatr 1993;122:37-45.

8. Zamboni G, Antoniazzi F, Radetti G, Musumeci C, Tatò L. Effects of two different regimens of recombinant human growth hormone therapy on the bone mineral density of patients with growth hormone deficiency. J Pediatr 1991;119:483-5.

9. Henneman PH, Forbes AP, Moldawer M, Dempsey EF, Carroll EL. Effects of human growth hormone in man. J Clin Invest 1960;39:1223-38.

10. Albertsson-Wikland K, Aronson AS, Gustafsson J, et al. Dose-dependent effect of growth hormone on final height in children with short stature without growth hormone deficiency. J Clin Endocrinol Metab 2008; $93: 4342-50$.

11. Benso L, Vannelli S, Pastorin L, Benso A, Milani S. Variation of bone age progression in healthy children. Acta Paediatr Suppl 1997;423:109-12.

12. Todd TW. Atlas av Skeletal Maturation (Hand). St Louis, MO: Mosby, 1937.

13. Martin DD, Wit JM, Hochberg Z, et al. The use of bone age in clinical practice - part 1. Horm Res Paediatr 2011;76:1-9.

14. Bull RK, Edwards PD, Kemp PM, Fry S, Hughes IA. Bone age assessment: a large scale comparison of the Greulich and Pyle, and Tanner and Whitehouse (TW2) methods. Arch Dis Child 1999;81:172-3.

15. Kriström B, Aronson AS, Dahlgren J, et al. Growth hormone (GH) dosing during catch-up growth guided by individual responsiveness decreases growth response variability in prepubertal children with GH deficiency or idiopathic short stature. J Clin Endocrinol Metab 2009;94:483-90.

16. Wikland KA, Kriström B, Rosberg S, Svensson B, Nierop AF. Validated multivariate models predicting the growth response to GH treatment in individual short children with a broad range in GH secretion capacities. Pediatr Res 2000;48:475-84.

17. Ankarberg-Lindgren C, Norjavaara E. Estradiol in pediatric endocrinology. Am J Clin Pathol 2009;132:978-80.

18. Martin DD, Neuhof J, Jenni OG, Ranke MB, Thodberg HH. Automatic determination of left- and right-hand bone age in the First Zurich Longitudinal Study. Horm Res Paediatr 2010;74:50-5.

19. Thodberg HH, Kreiborg S, Juul A, Pedersen KD. The BoneXpert method for automated determination of skeletal maturity. IEEE Trans Med Imaging 2009;28:52-66.

20. Hochberg Z. Growth hormone and IGF-I in growth plate growth. Curr Med Liter: Growth Growth Factors 1990;5:127-30.

21. Lewinson D, Shenzer P, Hochberg Z. Growth hormone involvement in the regulation of tartrate-resistant acid phosphatase-positive cells that are active in cartilage and bone resorption. Calcif Tissue Int 1993;52:216-21.

22. Even L, Bronstein V, Hochberg Z. Bone maturation in girls with Turner's syndrome. Eur J Endocrinol 1998;138:59-62.

23. Wikland KA, Luo ZC, Niklasson A, Karlberg J. Swedish population-based longitudinal reference values from birth to 18 years of age for height, weight and head circumference. Acta Paediatr 2002;91:739-54.

24. Jansson C, Boguszewski C, Rosberg S, Carlsson L, Albertsson-Wikland K. Growth hormone (GH) assays: influence of standard preparations, GH isoforms, assay characteristics, and GH-binding protein. Clin Chem 1997;43:950-6.

25. Löfqvist C, Andersson E, Gelander L, Rosberg S, Blum WF, Albertsson Wikland K. Reference values for IGF-I throughout childhood and adolescence: a model that accounts simultaneously for the effect of gender, age, and puberty. J Clin Endocrinol Metab 2001;86:5870-6.

26. Karlberg J. On the construction of the infancy-childhood-puberty growth standard. Acta Paediatr Scand Suppl 1989;356:26-37.

27. Karlberg J, Luo ZC, Albertsson-Wikland K. Body mass index reference values (mean and SD) for Swedish children. Acta Paediatr 2001;90:1427-34.

28. Luo ZC, Albertsson-Wikland K, Karlberg J. Target height as predicted by parental heights in a population-based study. Pediatr Res 1998;44:563-71. 